\title{
Association of vitamin D deficiency with COVID-19 severity and mortality in Iranian people: a prospective observational study
}

\author{
Alireza Fatemi ${ }^{1}$, Seyed Hossein Ardehali ${ }^{2}$, Ghazaleh Eslamian ${ }^{3}$, Morvarid Noormohammadi ${ }^{4}$, Shirin Malek ${ }^{5}$ \\ ${ }^{1}$ Men's Health and Reproductive Health Research Center, Shahid Beheshti University of Medical Sciences, Tehran; ${ }^{2}$ Department of Anesthesiology and Critical \\ Care, Shohadaye Tajrish Hospital, Shahid Beheshti University of Medical Sciences, Tehran; ${ }^{3}$ Department of Cellular and Molecular Nutrition, Faculty of Nutrition \\ and Food Technology, National Nutrition and Food Technology Research Institute, Shahid Beheshti University of Medical Sciences, Tehran; ${ }^{4}$ Student Research \\ Committee, Faculty of Nutrition and Food Technology, National Nutrition and Food Technology Research Institute, Shahid Beheshti University of Medical Sciences, \\ Tehran, Iran; ${ }^{5}$ Department of Nutrition and Food Science, California State University, Chico, CA, USA
}

Background: As the coronavirus disease 2019 (COVID-19) pandemic continues to escalate, it is important to identify the prognostic factors related to increased mortality and disease severity. To assess the possible associations of vitamin D level with disease severity and survival, we studied 248 hospitalized COVID-19 patients in a single center in a prospective observational study from October 2020 to May 2021 in Tehran, Iran.

Methods: Patients who had a record of their 25-hydroxyvitamin D level measured in the previous year before testing positive with COVID-19 were included. Serum 25-hydroxyvitamin D level was measured upon admission in COVID-19 patients. The associations between clinical outcomes of patients and 25-hydroxyvitamin D level were assessed by adjusting for potential confounders and estimating a multivariate logistic regression model.

Results: The median (interquartile range) age of patients was 60 years (44-74 years), and 53\% were male. The median serum 25-hydroxyvitamin $D$ level prior to admission decreased with increasing COVID-19 severity $(P=0.009)$. Similar findings were obtained when comparing median serum 25-hydroxyvitamin $D$ on admission between moderate and severe patients $(P=0.014)$. A univariate logistic regression model showed that vitamin $D$ deficiency prior to COVID-19 was associated with a significant increase in the odds of mortality (odds ratio, 2.01; $P=0.041$ ). The multivariate Cox model showed that vitamin $D$ deficiency on admission was associated with a significant increase in risk for mortality (hazard ratio, 2.35; $\mathrm{P}=0.019$ ).

Conclusions: Based on our results, it is likely that deficient vitamin D status is associated with increased mortality in COVID-19 patients. Thus, evaluating vitamin D level in COVID-19 patients is warranted.

Key Words: 25-hydroxyvitamin D; COVID-19; critical care outcomes; SARS-CoV-2

\section{INTRODUCTION}

Coronavirus disease 2019 (COVID-19), caused by severe acute respiratory syndrome coronavirus 2 (SARS-CoV-2), emerged in late 2019, and rapidly reached pandemic levels in 2020, resulting in more than 3,000,000 deaths worldwide [1]. The ongoing COVID-19 pandem-

\section{Original Article}

Received: May 12, 2021

Revised: August 5, 2021

Accepted: August 6, 2021

\section{Corresponding author}

Ghazaleh Eslamian

Department of Cellular and Molecular Nutrition, Faculty of Nutrition and Food Technology, National Nutrition and Food Technology Research Institute, Shahid Beheshti University of Medical Sciences, No 7, Hafezi St, Farahzadi Blvd, P.O. Box 19395-4741, Tehran 1981619573, Iran Tel: +98-21-22360658

Fax: +98-21-22360657

E-mail:gh.eslamian@sbmu.ac.ir

Copyright (C) 2021 The Korean Society of Critical Care Medicine

This is an Open Access article distributed under the terms of Creative Attributions Non-Commercial License (https:// creativecommons.org/li-censes/by-nc/4.0/) which permits unrestricted noncommercial use, distribution, and reproduction in any medium, provided the original work is properly cited. 
ic poses major challenges to healthcare systems globally. The clinical presentation of COVID-19 encompasses varied symptoms ranging from asymptomatic, mild to severe illness, including death [2]. To date, elucidating the mechanisms of this variability is crucial to determining the prognostic factors related to the higher mortality and disease severity.

Vitamin D deficiency and insufficiency are highly prevalent and affect almost one billion children and adults worldwide [3]. Beyond the established connection between vitamin D deficiency and mineral homeostasis, 1,25-dihydroxyvitamin D3, the active form of vitamin D, is a pluripotent hormone and key modulator of both innate and adaptive immunity [4]. One review showed that vitamin D has modulatory and regulatory roles in the risk of respiratory viral infections [5], but its causal role in COVID-19 infection is not known. The anti-inflammatory effects of vitamin D and its inhibitory role in the renin-angiotensin system could control immunity and oxidative reactions against COVID-19 infection or progression [6]. Additionally, evidence shows a possible immunological role of vitamin $\mathrm{D}$ that can lead to an increase in cellular immunity by inducing antimicrobial peptides [7]. These peptides, such as cathelicidin, destroy pathogens by disrupting their cellular membranes [8,9]. Epidemiological studies have shown that vitamin $\mathrm{D}$-deficient populations have a higher prevalence of COVID-19 [10]. Two recent meta-analyses indicated a positive association of vitamin $\mathrm{D}$ deficiency with increased risk of COVID-19 infection [11] and severity [12].

A growing body of evidence supports that vitamin D deficiency aggravates COVID-19. However, the understanding is limited and inconsistent. Therefore, the current study had two main objectives. First, to present the association of vitamin D status prior to COVID-19 infection with disease severity and survival in COVID-19 hospitalized patients. Second, to determine the possible association between admission serum level of vitamin D and COVID-19 severity, including mortality. We hypothesized that patients with previous vitamin $\mathrm{D}$ deficiency were deficient at COVID-19 diagnosis.

\section{MATERIALS AND METHODS}

The study was carried out in accordance with the Declaration of Helsinki and its subsequent amendments. It was approved by the Ethics Committee of Shahid Beheshti University of Medical Sciences (No. IR.SBMU.RETECH.REC.1399.884). Written informed consent was obtained from all patients prior to inclusion in the study.

\section{KEY MESSAGES}

- Vitamin D deficiency was associated with increased mortality in coronavirus disease 2019 (COVID-19) patients.

- Deficient vitamin D status was associated with increased COVID-19 severity.

\section{Study Design and Participants}

This single-center, prospective, observational study was conducted at a university-affiliated hospital from October 2020 to May 2021 in Tehran, Iran. A total of 248 patients who met the following criteria was included: hospitalized patients with positive, real-time, polymerase chain reaction (PCR) test results for COVID-19 based on the World Health Organization interim guidance [13] and chest computed tomography (CT); age 18 years or older; presence of clinical symptoms leading to hospitalization according to the national protocol that included patients with moderate and severe conditions (respiratory rate $[\mathrm{RR}]>30$ times/min, room-air oxygen saturation $<93 \%$, ratio of arterial oxygen partial pressure to fractional inspired oxygen $\left[\mathrm{PaO}_{2} / \mathrm{FiO}_{2}\right]<300 \mathrm{~mm} \mathrm{Hg}$ ); and patients who had a 25-hydroxyvitamin D level measured in the year prior to testing positive for COVID-19. Exclusion criteria were as follows: pregnancy; current breastfeeding; under vitamin D treatment at three months before COVID-19; death or discharge within 24 hours of hospital admission; transfer from another hospital; and end-stage renal disease, end-stage liver disease, and/or parathyroid disease on admission.

\section{Measurements}

Data on demographic features, past medical history, clinical symptoms, and clinical outcomes were collected using a checklist. Participants were asked to submit their most recent vitamin D level within one year before their first positive COVID-19 test. Laboratory assessments consisted of complete blood count, serum 25-hydroxycholecalciferol, and C-reactive protein (CRP) measured within 24 hours of hospital admission. Venous blood was drawn in the morning from an antecubital vein. Blood samples were collected in ethylenediaminetetraacetic acid (EDTA)-containing tubes and kept at room temperature for 15-30 minutes. Plasma was centrifuged $(3,000 \mathrm{rpm})$ for 10 minutes at $4^{\circ} \mathrm{C}$. Consequently, serum samples obtained were stored at $-20^{\circ} \mathrm{C}$ until laboratory evaluation. 
Serum 25-hydroxyvitamin D concentration was measured with the enzyme-linked immunosorbent assay (ELISA) method using a Monobind kit (Monobind Inc., Lake Forest, CA, USA), based on the kit instructions. We categorized serum 25 - hydroxycholecalciferol level as deficient when $<20 \mathrm{ng} / \mathrm{ml}$ and 1,25-dihydroxycholecalciferol level when $<18 \mathrm{pg} / \mathrm{ml}$. Vitamin D level $\geq 20 \mathrm{ng} / \mathrm{ml}$ or $\geq 18 \mathrm{pg} / \mathrm{ml}$ was categorized as not deficient [14]. The D-dimer and CRP levels were measured by chemiluminescent immunoassay and immunoturbidimetric assay, respectively. Severe COVID-19 was defined as any one of the following criteria: $\mathrm{RR} \geq 30$ breaths $/ \mathrm{min}, \mathrm{PaO}_{2} / \mathrm{FIO}_{2}$ ratio $<300 \mathrm{~mm} \mathrm{Hg}$, arterial blood oxygen saturation $\left(\mathrm{SaO}_{2}\right) \leq 93 \%$ in the resting state, and/or lung infiltrates in $>50 \%$ of the lung field within 24-48 hours from onset of symptoms [15].

\section{Statistical Analysis}

Statistical analysis was performed using IBM SPSS ver. 20.0 (IBM Corp., Armonk, NY, USA). Differences were defined as statistically significant at $\mathrm{P}<0.05$. All $\mathrm{P}$-values were considered two-tailed. Kolmogorov-Smirnov test, histogram, and Q-Q plot were used to verify the normal distribution of continuous variables. Quantitative data were expressed as median (Q1Q3) and qualitative data as number (\%). The differences in distribution of categorical variables were analyzed using chisquare test, whereas the Mann-Whitney test was performed to assess differences in the distribution of non-normal variables.

To determine the relationship between serum level 25-hydroxyvitamin D deficiency prior to COVID-19 and clinical outcome (death vs. discharge), univariate and multivariate logistic regression models were performed. Odds ratio (OR) and $95 \%$ confidence interval (CI) were calculated to show the intensity and direction of the relationship. Eventually, considering "death" as the event and "time to death/discharge" as event time, survival and proportional hazards Cox regression analyses were used to investigate the effect of admission 25-hydroxyvitamin D deficiency on the hazard ratio (HR) of death in patients with COVID-19 in univariate and multivariate models. The following variables were adjusted in the second model of both regressions: body mass index, sex, age, COVID-19 severity, CRP, and number of comorbidities related to vitamin D metabolism and/or COVID-19, including diabetes, chronic kidney disease, depression, hypertension, chronic pulmonary disease, pulmonary circulation disorders, liver disease, and immunosuppression.

\section{RESULTS}

During the study period, 248 patients provided a record of vitamin D level measured within the previous year prior to testing positive for COVID-19. Figure 1 shows a study flow diagram. The median (interquartile range) age was 60 years (4474 years), and there were 132 male participants (53\%). Among the total patients, 59 (23.8\%) did not have any comorbidity, and 109 (44\%) and 133 (53.6\%) had vitamin D deficiency within one year before and after COVID-19 testing, respectively. Demographic and clinical characteristics of participants are listed in Table 1 including vitamin D classification prior to COVID-19 and at admission. Study participants differed in terms of age, severity of COVID-19, and D-dimer level across the two vitamin D groups. There were statistically significant differences for mortality between the vitamin D deficient before COVID-19 group (22.9\%) and the vitamin D non-deficient group (12.9\%) $(\mathrm{P}=0.039)$. Similar results were obtained between the vitamin $\mathrm{D}$ deficient at admission group (22.6\%) and the vitamin D non-deficient group (11.3\%) $(\mathrm{P}=0.020)$.

Among the 109 patients who were vitamin D deficient one year before admission, 42 were in the sufficient group at the time of COVID-19 diagnosis, and 67 remained vitamin D deficient. Mortality was significantly higher in vitamin D deficient patients $(21 / 67,31 \%)$ than in the sufficient group $(4 / 42,9.5 \%)$ $(\mathrm{P}=0.008)$. The hospital length of stay was significantly shorter in the sufficient group patients than in the deficient group (7 [5-12.2] vs. 12 [6-15], $\mathrm{P}=0.018$ ).

Figure 2 depicts the comparison of the vitamin D level measured between moderate and severe COVID-19 patients at 1 year before diagnosis and at admission. Median serum 25-hydroxyvitamin D measured one year before COVID-19 decreased with increasing COVID-19 severity (22 [15-32] vs. 19 [11-26], $\mathrm{P}=0.009)$. Similar results were obtained when comparing median serum 25-hydroxyvitamin D at admission between moderate and severe patients $(20$ [12-25]) vs. 15 [8-25], $\mathrm{P}=0.014)$.

Tables 2 and 3 show the odds and HRs of death by 25-hydroxyvitamin D deficiency in patients prior to COVID-19 infection and at admission, respectively. Univariate logistic regression showed that patients with vitamin D deficiency $(<20$ $\mathrm{ng} / \mathrm{ml}$ ) at 1 year before COVID-19 had significantly higher odds of death (OR, 2.01; 95\% CI, 1.03-3.90; $\mathrm{P}=0.041$ ). However, after adjustment for confounders, the association was not significant (OR, 1.94; 95\% CI, 0.94-4.01; $\mathrm{P}=0.074$ ). In both univariate and multivariate Cox models, vitamin $\mathrm{D}$ deficient sta- 


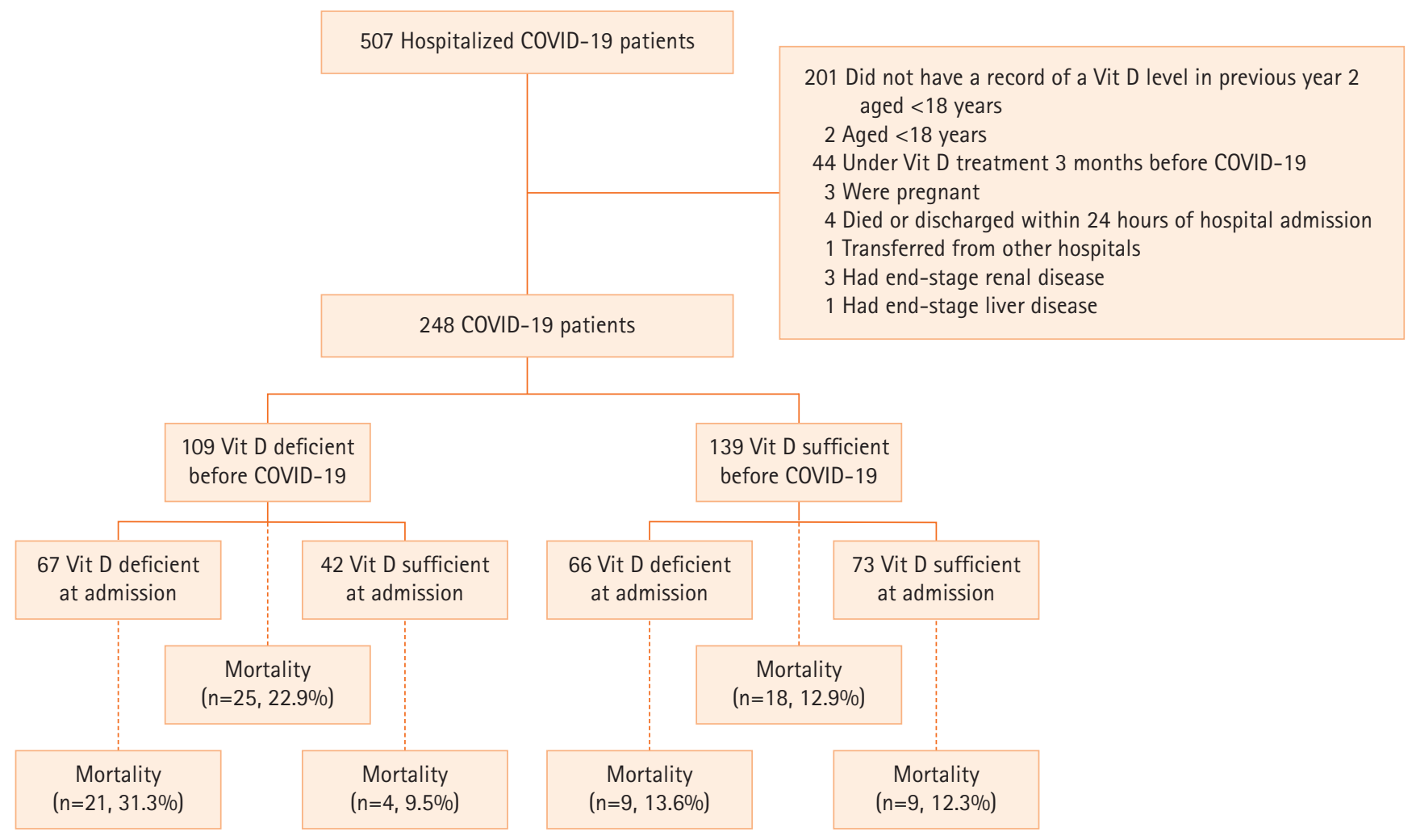

Figure 1. Flowchart of patient selection and mortality based on vitamin D (Vit D) status before and after coronavirus disease 2019 (COVID-19).

tus at admission increased the HR of death (HR, 2.18; 95\% CI, 1.12-4.26; $\mathrm{P}=0.023$ and $\mathrm{HR}, 2.35 ; 95 \% \mathrm{CI}, 1.15-4.78 ; \mathrm{P}=0.019$, respectively).

\section{DISCUSSION}

This study was designed to determine the association of vitamin D status prior to exposure to COVID-19 with disease severity and survival and to determine the association of admission serum level of vitamin $\mathrm{D}$ with disease severity and mortality in COVID-19 hospitalized patients. Our main finding is that COVID-19 patients with vitamin D deficiency upon admission were at substantially higher risk of mortality than were COVID-19 patients with sufficient levels. However, this association was not significant in patients with deficient vitamin D level before COVID-19 testing compared with patients with sufficient vitamin D status.

The advent of COVID-19 created awareness among researchers regarding the role of vitamin $\mathrm{D}$ in disease severity. One of the first ecological studies showed a negative correlation between vitamin D level and number of COVID-19 cases and mortality caused by this disease in various European countries [16]. D'Avolio et al. [17] reported that 25-hydroxyvitamin D concentration was lower in patients with positive PCR for SARS-CoV-2 compared with patients that had negative PCR. Meltzer et al. [18] found that deficient vitamin D status was associated with increased COVID-19 risk in a Chicago population. Our results support two recent meta-analyses that show a positive association of vitamin $\mathrm{D}$ deficiency with severity of COVID-19 [12] and with increased risk of COVID-19 infection [11]. In line with our result, Luo et al. [6] found a significant association between vitamin D deficiency and COVID-19 severity in a Chinese population. Furthermore, Radujkovic et al. [19] demonstrated an association between vitamin D deficiency and severity of and mortality from COVID-19 in a German population. However, Tehrani et al. [20] showed no statistical difference in vitamin D level between Iranian COVID-19 patients who died at the hospital and those who improved. Furthermore, Murai et al. [21], in a double-blind, randomized, placebo-controlled trial, demonstrated that a single high dose of vitamin D3 did not significantly improve clinical outcomes in patients with moderate to severe COVID-19.

In our study, most of the patients with previous vitamin $\mathrm{D}$ deficiency remained deficient at COVID-19 diagnosis. Patients 
Table 1. The demographic, clinical, and paraclinical characteristics of overall patients with COVID-19 and stratified by vitamin D level

\begin{tabular}{|c|c|c|c|c|c|c|c|}
\hline \multirow{3}{*}{ Variable } & \multirow{3}{*}{ Overall } & \multicolumn{3}{|c|}{1 Year before COVID-19 positive test } & \multicolumn{3}{|c|}{ At admission } \\
\hline & & \multicolumn{3}{|c|}{ Vitamin D classification } & \multicolumn{3}{|c|}{ Vitamin D classification } \\
\hline & & $<20 \mathrm{ng} / \mathrm{mL}$ & $\geq 20 \mathrm{ng} / \mathrm{mL}$ & P-value & $<20 \mathrm{ng} / \mathrm{mL}$ & $\geq 20 \mathrm{ng} / \mathrm{mL}$ & P-value \\
\hline No. of patients & 248 & 109 & 139 & & 133 & 115 & \\
\hline Age (yr) & $60(44-74)$ & $65(49-75)$ & $55(38-70)$ & $0.002^{a, b}$ & $61(47-75)$ & $58(36-70)$ & $0.033^{\mathrm{a}, \mathrm{b}}$ \\
\hline Sex & & & & $0.439^{c}$ & & & $0.957^{c}$ \\
\hline Male & $132(53.2)$ & $55(50.5)$ & $77(55.4)$ & & $71(53.4)$ & $61(53)$ & \\
\hline Female & $116(46.8)$ & $54(49.5)$ & $62(44.6)$ & & $62(46.6)$ & $54(47)$ & \\
\hline Educational level & & & & $0.461^{c}$ & & & $0.757^{c}$ \\
\hline Primary/secondary school & $38(15.3)$ & 20 (18.3) & $18(12.9)$ & & $20(15)$ & 18 (15.7) & \\
\hline Bachelor's degree & $167(67.3)$ & $72(66.1)$ & $95(68.3)$ & & $92(69.2)$ & 75 (65.2) & \\
\hline Master's/doctoral degree & $43(17.3)$ & $17(15.6)$ & $26(18.7)$ & & $21(15.8)$ & $22(19.1)$ & \\
\hline Severity of COVID-19 & & & & $0.006^{a, c}$ & & & $0.018^{\mathrm{a}, \mathrm{c}}$ \\
\hline Moderate & $162(65.3)$ & $61(56)$ & $101(72.7)$ & & $78(58.6)$ & $84(73)$ & \\
\hline Severe & $86(34.7)$ & $48(44)$ & $38(27.3)$ & & $55(41.4)$ & $31(27)$ & \\
\hline Body mass index $\left(\mathrm{kg} / \mathrm{m}^{2}\right)$ & $27.5(25-33.5)$ & $26.1(25-33.2)$ & $28(25-33.8)$ & $0.156^{b}$ & $27.2(25-33.8)$ & $27.5(25-32.7)$ & $0.897^{b}$ \\
\hline Body mass index $\geq 30 \mathrm{~kg} / \mathrm{m}^{2}$ & $93(37.5)$ & $35(32.1)$ & $58(41.7)$ & $0.121^{\mathrm{c}}$ & $52(39.1)$ & $41(35.7)$ & $0.576^{c}$ \\
\hline \multicolumn{8}{|l|}{ Comorbidity } \\
\hline Diabetes & $55(22.2)$ & $28(25.7)$ & $27(19.4)$ & $0.239^{c}$ & $32(24.1)$ & $23(20)$ & $0.443^{c}$ \\
\hline Hypertension & $83(33.5)$ & $41(37.6)$ & $42(30.2)$ & $0.220^{c}$ & $42(31.6)$ & $41(35.7)$ & $0.498^{c}$ \\
\hline Pulmonary circulation disorder & $17(6.9)$ & $9(8.3)$ & $8(5.8)$ & $0.439^{c}$ & $8(6)$ & $9(7.8)$ & $0.574^{c}$ \\
\hline Chronic pulmonary disease & $63(25.4)$ & 25 (22.9) & $38(27.3)$ & $0.429^{c}$ & $36(27.1)$ & $27(23.5)$ & $0.517^{c}$ \\
\hline Chronic kidney disease & $50(20.2)$ & $25(22.9)$ & $25(18)$ & $0.335^{c}$ & $28(21.1)$ & $22(19.1)$ & $0.707^{c}$ \\
\hline Liver disease & 22 (8.9) & $10(9.2)$ & $12(8.6)$ & $0.882^{c}$ & $9(6.8)$ & 13 (11.3) & $0.210^{c}$ \\
\hline Immunocompromised state & $58(23.4)$ & $30(27.5)$ & $28(20.1)$ & $0.173^{c}$ & $26(19.5)$ & $32(27.8)$ & $0.125^{c}$ \\
\hline Depression & 49 (19.8) & $27(24.8)$ & $22(15.8)$ & $0.079^{c}$ & 31 (23.3) & 18 (15.7) & $0.131^{\mathrm{c}}$ \\
\hline \multicolumn{8}{|l|}{ Laboratory data } \\
\hline Total leucocyte count & $\begin{array}{c}7,856 \\
(5,856-11,165)\end{array}$ & $\begin{array}{c}8,002 \\
(5,929-12,183)\end{array}$ & $\begin{array}{c}7,850 \\
(5,854-10,901)\end{array}$ & $0.403^{b}$ & $\begin{array}{c}8,502 \\
(5,856-12,735)\end{array}$ & $\begin{array}{c}7,660 \\
(5,803-10,012)\end{array}$ & $0.160^{b}$ \\
\hline Lymphocyte count & $22.8(17-31.5)$ & $22.8(17-31.7)$ & $22.8(17-30.8)$ & $0.877^{b}$ & $23.3(16.7-35.6)$ & $22.3(17-29.1)$ & $0.464^{b}$ \\
\hline CRP level (mg/dl) & $4.50(3.35-6.08)$ & $5.01(3.66-6.31)$ & $4.40(3.21-6.01)$ & $0.052^{b}$ & $5.02(4.01-6.31)$ & $4.03(2.51-5.90)$ & $0.001^{a, b}$ \\
\hline D-dimer (ng/ml) & $854(522-1,240)$ & $874(521-1,499)$ & $852(525-987)$ & $0.027^{a, b}$ & $874(755-1,437)$ & $854(485-984)$ & $0.002^{\mathrm{a}, \mathrm{b}}$ \\
\hline $\mathrm{O}_{2}$ saturation $(\%)$ & $88(85-89)$ & $87(85-89)$ & 88 (87-89) & $0.066^{b}$ & 88 (86-89) & $87(85-90)$ & $0.144^{b}$ \\
\hline \multicolumn{8}{|l|}{ Clinical outcome } \\
\hline Mortality & $43(17.3)$ & 25 (22.9) & 18 (12.9) & $0.039^{a, c}$ & $30(22.6)$ & $13(11.3)$ & $0.020^{a, c}$ \\
\hline Hospital length of stay (day) & $9(7-14)$ & $9(5-14)$ & $9(7-15)$ & $0.062^{b}$ & $9(7-14)$ & $8(6-14)$ & $0.197^{b}$ \\
\hline
\end{tabular}

Values are presented as median (interquartile range) or number (\%).

COVID-19: coronavirus disease 2019; CRP: C-reactive protein.

${ }^{\text {a }}$ Statistically significant; ${ }^{b}$ Mann-Whitney test; ${ }^{c}$ Chi-square test.

whose vitamin D status changed from deficient to sufficient had better clinical outcomes. Moreover, vitamin D deficiency was associated with either COVID-19 severity or linked mortality. Therefore, our findings suggest that treatment of vitamin D deficiency can prevent COVID-19 death.

Vitamin D has shown not only anti-inflammatory and anti-microbial properties, but also is an immunomodulator.
Vitamin D deficiency can augment COVID-19 severity and mortality by triggering a hyperinflammatory state and a cytokine storm. Data show that vitamin D deficiency in COVID-19 patients presents significantly higher levels of inflammatory and coagulation biomarkers including CRP, D-dimer, interleukin-6, tumor necrosis factor- $\alpha$, fibrinogen, and ferritin [22-24]. Furthermore, vitamin $\mathrm{D}$ has been implicated to negatively reg- 


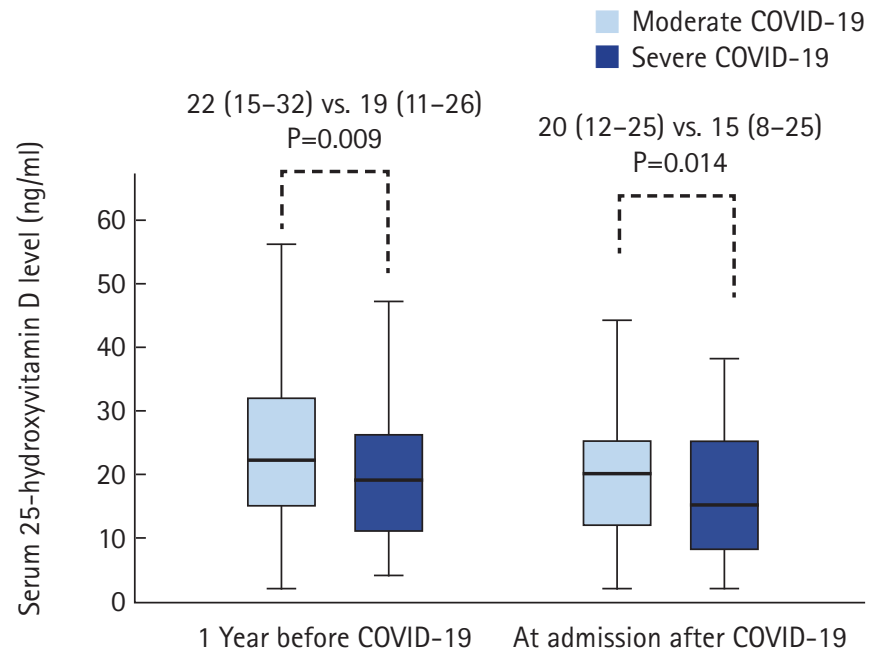

Figure 2. Median serum 25-hydroxyvitamin D level according to coronavirus disease 2019 (COVID-19) severity category. Values are presented as median (interquartile range). P-values were calculated using the Mann-Whitney U-test. ulate the renin-angiotensin system. Cell entry of SARS-CoV-2 depends on binding of angiotensin-converting enzyme 2 (ACE2) as a receptor. Vitamin D inhibits the synthesis of renin and increases ACE2 expression and angiotensin (1-7) production in the lung, decreasing the risk of SARS-CoV-2 infection and prevent COVID-19 symptoms [24,25].

This study had several limitations. First, vitamin D deficiency can be associated closely with a range of chronic diseases or behavioral characteristics that possibly increase COVID-19 risk. Second, the data were from those who had a 25- hydroxyvitamin D level measured in the year before infection with COVID-19 and were not treated with vitamin D. Third, the study was conducted in a single center located in Tehran, an area with a high prevalence of vitamin $\mathrm{D}$ deficiency. Fourth, the study might be prone to selection bias; if vitamin D deficiency testing was more likely in COVID-19 patients than non-infected patients, this might introduce a selection bias.

Table 2. Univariate and multivariate logistic regression analyses of mortality affected by $25(\mathrm{OH}) \mathrm{D}$ deficiency at admission in patients with COVID-19

\begin{tabular}{|c|c|c|c|c|c|}
\hline \multirow{2}{*}{ Variable } & \multirow{2}{*}{ Dead } & \multicolumn{2}{|c|}{ Univariate analysis } & \multicolumn{2}{|c|}{ Multivariate analysis } \\
\hline & & OR $(95 \% \mathrm{Cl})$ & $\mathrm{P}$-value & OR $(95 \% \mathrm{Cl})$ & P-value \\
\hline Age (yr) & $67(45-75)$ & $0.98(0.96-1.01)$ & 0.115 & $0.99(0.97-1.02)$ & 0.542 \\
\hline Male & $21(48.8)$ & $1.24(0.64-2.39)$ & 0.526 & $1.20(0.59-2.46)$ & 0.598 \\
\hline $\mathrm{BMI}\left(\mathrm{kg} / \mathrm{m}^{2}\right)$ & $26.1(25.1-34.7)$ & $0.98(0.93-1.03)$ & 0.395 & $0.97(0.92-1.02)$ & 0.233 \\
\hline $\mathrm{CRP}(\mathrm{mg} / \mathrm{dl})$ & $4.3(3.3-5.6)$ & $1.12(0.93-1.34)$ & 0.249 & $1.19(0.97-1.47)$ & 0.103 \\
\hline Severe COVID-19 & $25(58.1)$ & $3.28(1.67-6.45)$ & 0.001 & $2.99(1.46-6.09)$ & 0.003 \\
\hline Number of comorbidities & $1(1-3)$ & $1.07(0.83-1.38)$ & 0.619 & $1.13(0.86-1.48)$ & 0.387 \\
\hline 25(OH)D prior to COVID-19 deficiency & $25(58.1)$ & $2.01(1.03-3.90)$ & 0.041 & $1.94(0.94-4.01)$ & 0.074 \\
\hline
\end{tabular}

Values are presented as median (interquartile range) or number (\%) unless otherwise indicated.

25(OH)D: 25-hydroxyvitamin D; COVID-19: coronavirus disease 2019; OR: odds ratio; Cl: confidence interval; BMI: body mass index; CRP: C-reactive protein.

${ }^{a}$ Multivariable analyses were conducted using logistic regression models utilizing the simultaneous method.

Table 3. Univariate and multivariate Cox regression analyses of mortality affected by admission 25(OH)D deficiency in patients with COVID-19

\begin{tabular}{|c|c|c|c|c|c|}
\hline \multirow{2}{*}{ Variable } & \multirow{2}{*}{ Dead } & \multicolumn{2}{|c|}{ Univariate analysis } & \multicolumn{2}{|c|}{ Multivariate analysis } \\
\hline & & HR $(95 \% \mathrm{Cl})$ & P-value & $\mathrm{HR}(95 \% \mathrm{Cl})$ & P-value \\
\hline Age (yr) & $67(45-75)$ & $1.02(1.01-1.04)$ & 0.031 & $1.01(0.99-1.03)$ & 0.355 \\
\hline Male & $21(48.8)$ & $1.23(0.68-2.25)$ & 0.491 & $1.12(0.59-2.14)$ & 0.721 \\
\hline BMI $\left(\mathrm{kg} / \mathrm{m}^{2}\right)$ & $26.1(25.1-34.7)$ & $1.03(0.99-1.08)$ & 0.156 & $1.03(0.98-1.08)$ & 0.197 \\
\hline $\mathrm{CRP}(\mathrm{mg} / \mathrm{dl})$ & $4.3(3.3-5.6)$ & $0.88(0.74-1.03)$ & 0.117 & $0.80(0.66-0.97)$ & 0.021 \\
\hline Severe COVID-19 & $25(58.1)$ & $3.45(1.79-6.65)$ & $<0.001$ & $2.90(1.46-5.77)$ & 0.002 \\
\hline Number of comorbidities & $1(1-3)$ & $0.94(0.74-1.18)$ & 0.574 & $1.03(0.81-1.31)$ & 0.802 \\
\hline 25(OH)D at admission deficiency & $30.0(69.8)$ & $2.18(1.12-4.26)$ & 0.023 & $2.35(1.15-4.78)$ & 0.019 \\
\hline
\end{tabular}

Values are presented as median (interquartile range) or number (\%) unless otherwise indicated.

25(OH)D: 25-hydroxyvitamin D; COVID-19: coronavirus disease 2019; HR: hazard ratio; Cl: confidence interval; BMI: body mass index; CRP: C-reactive protein.

${ }^{a}$ Multivariable analyses were conducted using Cox regression models utilizing the simultaneous method. 
Finally, the time difference between infection and admission was not taken into consideration; the quantitative variables were measured only upon admission.

In conclusion, the findings of this study provide evidence that vitamin D could be a factor in improving clinical outcome in COVID-19 patients. These findings have implications for future randomized clinical trials to assess the effects of vitamin D supplementation on clinical outcome in COVID-19 patients with vitamin D deficiency.

\section{CONFLICT OF INTEREST}

No potential conflict of interest relevant to this article was reported.

\section{ORCID}

Alireza Fatemi https://orcid.org/0000-0003-0671-7611 Seyed Hossein Ardehali

https://orcid.org/0000-0001-6656-3875

Ghazaleh Eslamian $\quad$ https://orcid.org/0000-0002-8960-5123 Morvarid Noormohammadi https://orcid.org/0000-0002-1971-8982

Shirin Malek https://orcid.org/0000-0002-1705-3884

\section{AUTHOR CONTRIBUTIONS}

Conceptualization: AF, SHA, GE. Data curation: GE, SM. Formal analysis: SHA, GE, MN. Funding acquisition: AF, SHA, GE, MN. Methodology: AF, SHA, GE, SM. Project administration: GE. Visualization: AF, MN. Writing-original draft: AF, SHA, GE. Writing-review \& editing: all authors.

\section{REFERENCES}

1. Worldometer. COVID-19 corona virus pandemic. Worldometer; 2021 [cited 2021 May 10]. Available from: https://www. worldometers.info/coronavirus/.

2. Weiss P, Murdoch DR. Clinical course and mortality risk of severe COVID-19. Lancet 2020;395:1014-5.

3. Holick MF. The vitamin D deficiency pandemic: approaches for diagnosis, treatment and prevention. Rev Endocr Metab Disord 2017;18:153-65.

4. Charoenngam N, Holick MF. Immunologic effects of vitamin D on human health and disease. Nutrients 2020;12:2097.

5. Zdrenghea MT, Makrinioti H, Bagacean C, Bush A, Johnston
SL, Stanciu LA. Vitamin D modulation of innate immune responses to respiratory viral infections. Rev Med Virol 2017;27:e1909.

6. Luo X, Liao Q, Shen Y, Li H, Cheng L. Vitamin D deficiency is associated with COVID-19 Incidence and disease severity in Chinese people [corrected]. J Nutr 2021;151:98-103.

7. Aslan MT, Aslan İÖ, Özdemir Ö. Letter to the editor: is vitamin d one of the key elements in COVID-19 days? J Nutr Health Aging 2020;24:1038-9.

8. Herr C, Shaykhiev R, Bals R. The role of cathelicidin and defensins in pulmonary inflammatory diseases. Expert Opin Biol Ther 2007;7:1449-61.

9. Agier J, Efenberger M, Brzezińska-Błaszczyk E. Cathelicidin impact on inflammatory cells. Cent Eur J Immunol 2015;40:22535.

10. Yisak H, Ewunetei A, Kefale B, Mamuye M, Teshome F, Ambaw B, et al. Effects of vitamin D on COVID-19 infection and prognosis: a systematic review. Risk Manag Healthc Policy 2021;14:31-8.

11. Liu N, Sun J, Wang X, Zhang T, Zhao M, Li H. Low vitamin D status is associated with coronavirus disease 2019 outcomes: a systematic review and meta-analysis. Int J Infect Dis 2021;104:58-64.

12. Pereira M, Dantas Damascena A, Galvão Azevedo LM, de Almeida Oliveira T, da Mota J. Vitamin D deficiency aggravates COVID-19: systematic review and meta-analysis. Crit Rev Food Sci Nutr 2020 Nov 4 [EPUB]. https://doi.org/10.1080/10408398. 2020.1841090 .

13. World Health Organization. Clinical management of severe acute respiratory infection when novel coronavirus (2019$\mathrm{nCoV}$ ) infection is suspected: interim guidance, 28 January 2020 [Internet]. Geneva: World Health Organization; 2020 [cited 2021 May 10]. Available from: https://apps.who.int/iris/ handle/10665/330893.

14. Holick MF, Binkley NC, Bischoff-Ferrari HA, Gordon CM, Hanley DA, Heaney RP, et al. Evaluation, treatment, and prevention of vitamin D deficiency: an Endocrine Society clinical practice guideline. J Clin Endocrinol Metab 2011;96:1911-30.

15. Bhatraju PK, Ghassemieh BJ, Nichols M, Kim R, Jerome KR, Nalla AK, et al. COVID-19 in critically ill patients in the Seattle Region: case series. N Engl J Med 2020;382:2012-22.

16. Ilie PC, Stefanescu S, Smith L. The role of vitamin D in the prevention of coronavirus disease 2019 infection and mortality. Aging Clin Exp Res 2020;32:1195-8.

17. D’Avolio A, Avataneo V, Manca A, Cusato J, De Nicolò A, Lucchini $\mathrm{R}$, et al. 25-Hydroxyvitamin D concentrations are low- 
er in patients with positive PCR for SARS-CoV-2. Nutrients 2020;12:1359.

18. Meltzer DO, Best TJ, Zhang H, Vokes T, Arora V, Solway J. Association of vitamin D status and other clinical characteristics with COVID-19 test results. JAMA Netw Open 2020;3:e2019722.

19. Radujkovic A, Hippchen T, Tiwari-Heckler S, Dreher S, Boxberger M, Merle U. Vitamin D deficiency and outcome of COVID-19 patients. Nutrients 2020;12:2757.

20. Tehrani S, Khabiri N, Moradi H, Mosavat MS, Khabiri SS. Evaluation of vitamin D levels in COVID-19 patients referred to Labafinejad hospital in Tehran and its relationship with disease severity and mortality. Clin Nutr ESPEN 2021;42:313-7.

21. Murai IH, Fernandes AL, Sales LP, Pinto AJ, Goessler KF, Duran CS, et al. Effect of a single high dose of vitamin D3 on hospital length of stay in patients with moderate to severe COVID-19: a randomized clinical trial. JAMA 2021;325:1053-60.
22. Infante M, Buoso A, Pieri M, Lupisella S, Nuccetelli M, Bernardin S, et al. Low vitamin d status at admission as a risk factor for poor survival in hospitalized patients with COVID-19: an Italian retrospective study. J Am Coll Nutr 2021 Feb 18 [Epub]. https://doi.org/10.1080/07315724.2021.1877580.

23. Jain A, Chaurasia R, Sengar NS, Singh M, Mahor S, Narain S. Analysis of vitamin D level among asymptomatic and critically ill COVID-19 patients and its correlation with inflammatory markers. Sci Rep 2020;10:20191.

24. Pinheiro MM, Fabbri A, Infante M. Cytokine storm modulation in COVID-19: a proposed role for vitamin D and DPP-4 inhibitor combination therapy (VIDPP-4i). Immunotherapy 2021;13:753-65.

25. Malek Mahdavi A. A brief review of interplay between vitamin $\mathrm{D}$ and angiotensin-converting enzyme 2: Implications for a potential treatment for COVID-19. Rev Med Virol 2020;30:e2119. 